\title{
The influence of high tensile bolts tightening torque on stress distribution in the bolted connection of rockfall barrier under impact load
}

\author{
Krzysztof Kuliński ${ }^{1, *}$, and Maciej Major ${ }^{1}$ \\ ${ }^{1}$ Częstochowa University of Technology, Faculty of Civil Engineering, ul. Akademicka 3, \\ 42-200 Częstochowa, Poland
}

\begin{abstract}
The paper presents the finite element method approach to determine stress distribution in rockfall barrier post with end to end-plate connection, assembled with high tensile bolts under two different types of impact load. For the analysis purposes typical fixed to the foundation, rockfall barrier post is adopted with 2,50 m height and sixty degrees slope to the horizontal ground line. One post end is fixed (welded) to the base plate - anchored to foundation, the second end is supported via retaining rope. The impact load applied exactly in the post mid-height and boulder caught via net in the mid-distance between two consecutive post are discussed. Four different locations of end to end-plate connection are analysed measuring from the fixed support i.e. dimension varies in the range of $0,30 \mathrm{~m}$ up to $0,60 \mathrm{~m}$ with $0,10 \mathrm{~m}$ step. Six high tensile bolts, zinc coated with 12.9 grade strength have been adopted in the connection. The stated boundary problem was solved by means of SolidWorks software.
\end{abstract}

\section{Introduction}

Rockfalls in mountains, on engineered slopes, mines etc. due to an unknown time of occurrence are hazardous phenomena causing serious threat for human lives, settlements, transportation and other infrastructure. The most significant influence on rockfall is triggered by the surrounding environment i.e. rainfalls [1], cycle freeze-and-thaw cycles [2] and progressive weathering [3]. The areas located at the junction of tectonic plates or volcanic grounds detect earthquakes as additional main factors [4]. It is worth noting that transportation infrastructure or facilities located nearby the rock slopes may also trigger a rock avalanche via emitted vibrations.

In the rockfall - exposed areas the major needs are an accurate prediction of rockfall runout, definition of possible threat to human lives or potential damage caused to infrastructure and then mitigation or possibly prevention of the hazardous phenomena. The crucial importance on planning the strength, supporting scheme and dimensions of barriers preventing individual or massive rock falling is observed with respect to in situ investigation of terrain and computer simulations [5-8]. An exemplary scheme of typical rockfall barrier with different supporting conditions is shown in Fig. 1.

*Corresponding author: kkulinski@bud.pcz.pl 


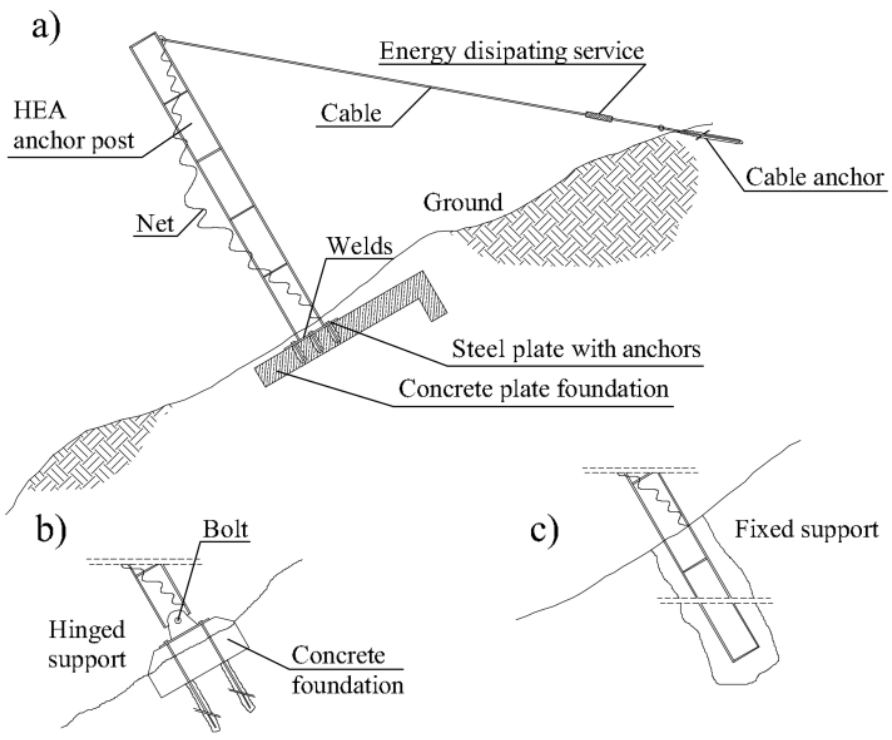

Fig. 1. Schemes of typically utilized rockfall barriers with different types of supports, a) barrier post fixed to the retaining concrete plate, b) hinged type of support, c) hammered post (fixed type).

In practice two different types of supports are applied i.e. the hinged support where barrier post may freely rotate in the slope direction (see Fig. 1b) and fixed support (see Fig. 1c). The barrier supporting scheme depends mainly on soil strength and the energy transferred via the falling rocks. Fixed supports due to transfer of momentum forces are utilized especially in bedrocks or in ground with relatively high bearing capacity to allow the posts to be grouted or even hammered into (see Fig. 1c). In the cases showing soil of a significantly lower strength than bedrock, gravels, sands special concrete retaining plate may be utilized to prevent barrier sliding (see Fig. 1a). It is worth noting that hinged barrier posts are easier to replace after stated exceeded deformations or any other stated damage than the fixed ones. In the hinged barriers energy is transferred mainly via the retaining ropes, while in self-supporting fixed posts energy is dissipated via profile deformation and net rigidity - the rest of the energy is transferred onto the concrete pedestal. The main advantage of self-supporting fixed posts is the possibility of omitting the retaining ropes, which eliminates the necessity of providing additional anchors upslope, however if the required ropes may significantly strengthen the system bearing capacity.

In the paper stress distribution is investigated in a fixed rockfall barrier post with end to end-plate connection under applied two different impact loads. The first type of loading concerns case in which boulder hits the post exactly, whereas the second type corresponds to the case in which boulder is caught by means of net. It is assumed that the post is rigidly connected (welded) to the base plate, consequently anchored to concrete retaining slab. Moreover, four different locations of barrier post end to end-plate connection are taken into considerations. All numerical calculations were performed with the use of SolidWorks software, with a simulation module fully based on finite element method.

\section{Numerical model assumptions}

For the numerical analysis purpose of the rockfall barrier post, a HEA240 profile made of S235JR steel grade class was chosen. The total length of mentioned post was assumed 
2,50 $\mathrm{m}$. Four different locations of barrier post end to end-plate connection measuring from the fixed support were considered i.e. 0,$30 ; 0,40 ; 0,50$ and $0,60 \mathrm{~m}$, respectively. The analysed variants of barrier post are presented in Fig. 2, where the numbers in parentheses denote modifications shown via dashed lines i.e. in variant II all dimensions remain same as in variant I, whereas end to end-plate connection is distanced $400 \mathrm{~mm}$ from the fixed end and one more area for eccentric load case was taken into consideration (see section A-A in Fig. 2).
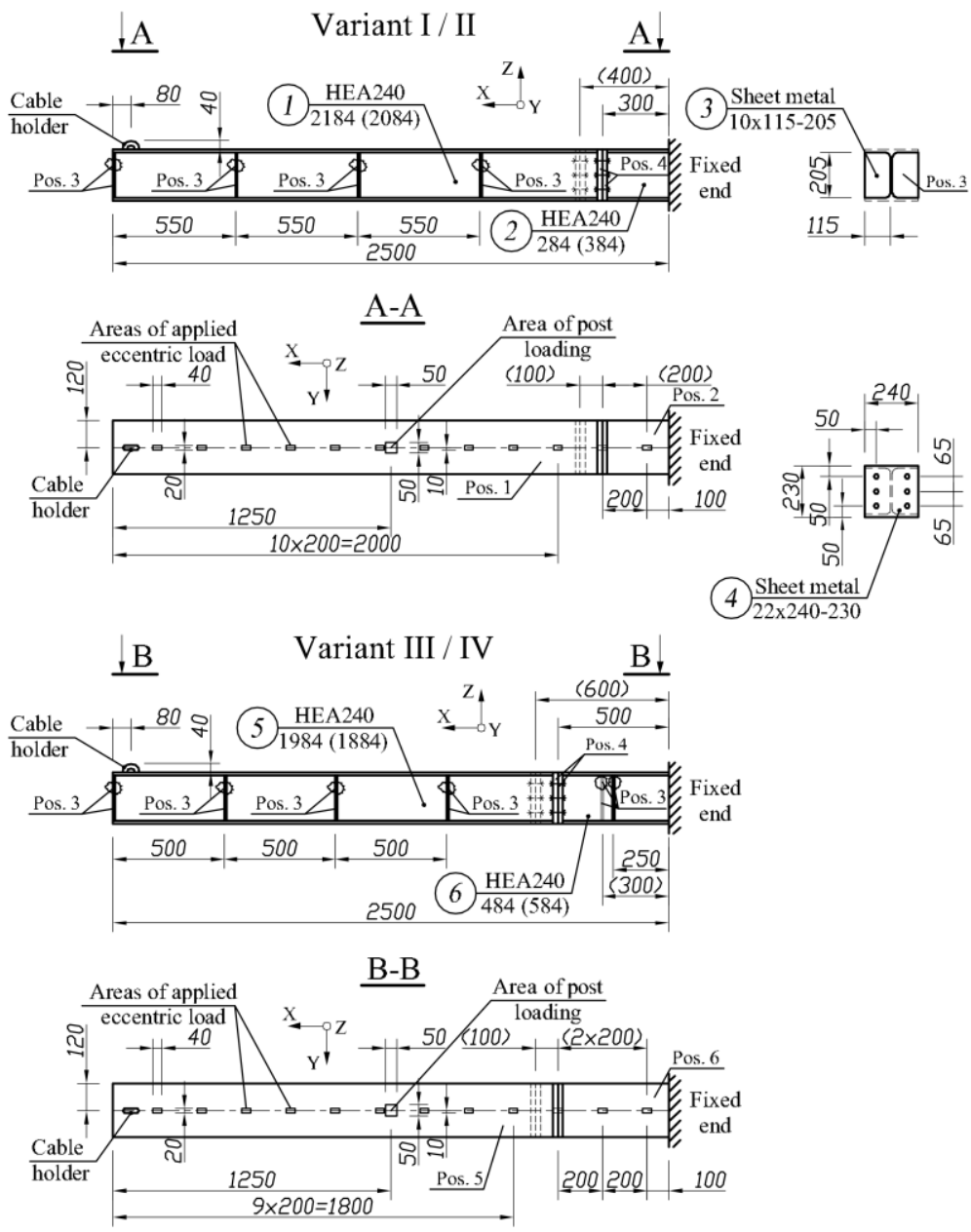

Fig. 2. Different variants of analysed fixed barrier post with variable location of end-plate connection.

According to the fact that the fixed type of rockfall barrier post was analysed, the end to end-plate connection was introduced to provide extra possibility of exchanging damaged via rockfall post element without the necessity of exchanging the whole post with also its foundation. In the end to end-plate connection six M24 12.9 grade high tensile bolts, electrically zinc plated were assumed. Connectors were arranged in two columns and three rows, where corner bolts were distanced from the metal sheet edges by $50 \mathrm{~mm}$ in the horizontal and vertical direction (see Fig. 2). Referring to the bolt manufacturer information [9] a tightening torque equal $1140 \mathrm{Nm}$ was applied to each bolt. Additionally, for each connector two washers were provided, one under the bolt head and one under the nut. Flat rounded washers with external diameter $\varnothing 44 \mathrm{~mm}$, internal diameter $\varnothing 26 \mathrm{~mm}$ and thickness 
$4 \mathrm{~mm}$ were introduced. On the basis of Polish national standard (PN-EN 1993-1-8:2006) connection meets all bearing capacity requirements with end-plate thickness assumed as $22 \mathrm{~mm}$.

For the purpose of analysis two different types of loading were assumed. Additionally, it was preliminary assumed that the mountainside is inclined at 30 and analysed post at 60 degrees measuring to the horizontal terrain line. Hence the most unfavourable moment distribution in HEA profile was obtained for perpendicular impact direction to the XYplane presented in Fig. 2. In the first case boulder impacts barrier post exactly in its midheight (see area of post loading in Fig. 2). The boulder was simplified to the concentrated force of a $1000 \mathrm{kN}$ value, distributed on the $50 \times 50 \mathrm{~mm}$ area. The mentioned force reached its maximum value at $0.02 \mathrm{~s}$ from the start of analysis, after that load value tends to zero till $0.50 \mathrm{~s}$. Such a simplification corresponds to the real case in which boulder hits the post, afterwards profile both elastically and plastically deforms under applied load and depending on the amount of accumulated elastic energy that energy is transferred backwards to the boulder. In the second loading case it was assumed that the boulder was caught via net in the middle point between two consecutive post and their mid-height. According to that only half of first case force value $-500 \mathrm{kN}$ was applied on the eccentricity. The posts were assumed to be spaced in the Y-axis direction by 3,00 m. Semi-rigid net fixing system was assumed with intermediate net supporting points distanced by $200 \mathrm{~mm}$. In order to simplify the numerical model a catching net was neglected in the analysis. Hence concentrated force was applied on the eccentricity. The point of action was located $1,50 \mathrm{~m}$ in the $\mathrm{Y}$-axis direction and $1,25 \mathrm{~m}$ in the $\mathrm{X}$-axis direction measuring from the point where longitudinal profile axis crosses YZ-plane with an applied fixed boundary condition. In the opposite Zaxis direction the mentioned force point of action was distanced by $0,25 \mathrm{~m}$ measuring from top surface of HEA beam flange. The force acting direction was also assumed as the most unfavourable - perpendicular to the XY-plane and opposite to the Z-axis. On the basis of performed numerical calculations and considerations concluded in $[10,11]$, maximum energy in the barriers is accumulated at approximately 0.15 up to $0.8 \mathrm{~s}$ depending on net rigidity and location of boulder impact. In the presented paper maximum energy accumulation was assumed at $0.5 \mathrm{~s}$, furtherly load was removed - force value equal 0 (boulder moving backwards under the influence of net elastic rigidity). The second and further boulder impacts under the gravity were neglected in the performed analysis, since maximum energy is transferred to the barrier via the first impact.

In the presented barrier posts in Fig. 2, following boundary conditions were adopted with respect to the Cartesian coordinate system: X, Y, Z-axis displacements and rotations fixed on the external YZ surface of HEA profile and Z-axis displacement fixed onto the bottom cylindrical surface of cable holder. Between the end-plates and washers/end-plates contact without penetration was assumed. Hex connectors were represented by SolidWorks bolt elements with specified alloy steel material and appropriate tightening torque equal $1140 \mathrm{Nm}$. Similar analysis with tightening torque equal $0 \mathrm{Nm}$ had to be performed in order to find the influence of this parameter on the obtained stress results. Moreover, the direction of force applied exactly on the HEA profile follows the post deformation, whereas concentrated force applied on eccentricity have constant direction. It is worth noting that the amount of energy transferred onto the catching net supporting areas in the case of eccentrically applied load depends on distance and deformation of host post.

In the SolidWorks software discretization of barrier posts have been performed with 3D-Solid 4-node tetrahedron finite elements. For S235JR steel grade elements the homogeneous, elastic and isotropic material was chosen with Young's modulus $E=210 \mathrm{GPa}$, Poisson's ratio $v=0.28$ and mass equal $7800 \mathrm{~kg} / \mathrm{m}^{3}$, respectively. Fine mesh with element size around $\sim 3 \mathrm{~mm}$ was used for washers, area under and near the washers' 
elements and near the applied boundary conditions. For the other part of the model an adaptive mesh from 3 up to $50 \mathrm{~mm}$ was used.

\section{Numerical results and discussion}

In this section numerical results concerning HMH stress results obtained in the end-plate connection under bolts washers are presented. The following nomenclature is used to identify appropriate model: Variant I denotes beam, where welded post to the steel foundation plate have $0,30 \mathrm{~m}$ and the assembled post height is $2,20 \mathrm{~m}$, Variant II $-0,40 \mathrm{~m}$ of welded post and $2,10 \mathrm{~m}$ of assembled post, Variant III $-0,50 \mathrm{~m} / 2,00 \mathrm{~m}$ and Variant IV $-0,60 \mathrm{~m} / 1,90 \mathrm{~m}$, respectively. For the sake of comparative analysis in which the influence of bolts tightening torque onto stress obtained values in end-plate connection is going to be discussed, absolute maximum HMH stress values were chosen from the areas located under corner hex bolts washers. The obtained HMH stress values for load applied directly to the HEA post at time $t=0.02 \mathrm{~s}$ were presented in Tab. 1. Values for load applied on eccentricity at time $t=0.50 \mathrm{~s}$ are shown in Tab. 2 .

Table 1. Absolute maximum HMH stress values under corner hex bolts washers for different end-plate connection location and two different values of tightening torque at $t=0,02 \mathrm{~s}$.

Impact load applied directly to the HEA post.

\begin{tabular}{|c|c|c|c|c|c|}
\hline $\begin{array}{c}\text { End-plate } \\
\text { belonging to: }\end{array}$ & $\begin{array}{c}\text { Tightening } \\
\text { torque } \\
{[\mathrm{Nm}]}\end{array}$ & $\begin{array}{c}\text { Variant I } \\
(30 / 220) \\
{[\mathrm{Pa}]}\end{array}$ & $\begin{array}{c}\text { Variant II } \\
(40 / 210) \\
{[\mathrm{Pa}]}\end{array}$ & $\begin{array}{c}\text { Variant III } \\
(50 / 200) \\
{[\mathrm{Pa}]}\end{array}$ & $\begin{array}{c}\text { Variant IV } \\
(60 / 190) \\
{[\mathrm{Pa}]}\end{array}$ \\
\hline \multirow{2}{*}{$\begin{array}{c}\text { Assembled } \\
\text { post }\end{array}$} & 0 & $1.115 \mathrm{E}+09$ & $9.122 \mathrm{E}+08$ & $7.274 \mathrm{E}+08$ & $5.203 \mathrm{E}+08$ \\
\cline { 2 - 6 } & 1140 & $1.298 \mathrm{E}+09$ & $1.026 \mathrm{E}+09$ & $7.754 \mathrm{E}+08$ & $5.385 \mathrm{E}+08$ \\
\hline \multirow{2}{*}{ Welded post } & 0 & $1.189 \mathrm{E}+09$ & $9.160 \mathrm{E}+08$ & $7.335 \mathrm{E}+08$ & $5.401 \mathrm{E}+08$ \\
\cline { 2 - 6 } & 1140 & $1.336 \mathrm{E}+09$ & $9.966 \mathrm{E}+08$ & $7.893 \mathrm{E}+08$ & $5.513 \mathrm{E}+08$ \\
\hline
\end{tabular}

Table 2. Absolute maximum HMH stress values under corner hex bolts washers for different end-plate connection location and two different values of tightening torque at $t=0,50 \mathrm{~s}$.

Barrier post subjected to the eccentrically applied load.

\begin{tabular}{|c|c|c|c|c|c|}
\hline $\begin{array}{c}\text { End-plate } \\
\text { belonging to: }\end{array}$ & $\begin{array}{c}\text { Tightening } \\
\text { torque } \\
{[\mathrm{Nm}]}\end{array}$ & $\begin{array}{c}\text { Variant I } \\
(30 / 220) \\
{[\mathrm{Pa}]}\end{array}$ & $\begin{array}{c}\text { Variant II } \\
(40 / 210) \\
{[\mathrm{Pa}]}\end{array}$ & $\begin{array}{c}\text { Variant III } \\
(50 / 200) \\
{[\mathrm{Pa}]}\end{array}$ & $\begin{array}{c}\text { Variant IV } \\
(60 / 190) \\
{[\mathrm{Pa}]}\end{array}$ \\
\hline \multirow{2}{*}{$\begin{array}{c}\text { Assembled } \\
\text { post }\end{array}$} & 0 & $1.222 \mathrm{E}+09$ & $9.624 \mathrm{E}+08$ & $7.990 \mathrm{E}+08$ & $6.424 \mathrm{E}+08$ \\
\cline { 2 - 6 } & 1140 & $1.258 \mathrm{E}+09$ & $9.844 \mathrm{E}+08$ & $8.360 \mathrm{E}+08$ & $6.954 \mathrm{E}+08$ \\
\hline \multirow{2}{*}{ Welded post } & 0 & $1.262 \mathrm{E}+09$ & $9.680 \mathrm{E}+08$ & $8.170 \mathrm{E}+08$ & $6.648 \mathrm{E}+08$ \\
\cline { 2 - 6 } & 1140 & $1.295 \mathrm{E}+09$ & $1.030 \mathrm{E}+09$ & $8.751 \mathrm{E}+08$ & $7.396 \mathrm{E}+08$ \\
\hline
\end{tabular}

In both tables the welded post denotes the post fixed to the foundation plate, whereas assembled post denotes the post supported with the retaining rope (see Fig. 2).

On the basis of HMH stress values presented in Tab. 1 and Tab. 2 it is clearly visible that the time to make the impact load reaches its maximum value, also makes the stress under the washer edges significantly exceed the steel yield stress. It should be noted here, that the stress concentration covered very small area and material under the washers was 
not ruptured. Comparison of the obtained results shows that the longer distance of end to end-plate connection from the foundation, the lower stress values are obtained, which is linked with lower value of bending moment. With a closer distance to the fixed support, moment value rapidly increases, thus the combination of shear forces and moments forces led to relatively higher values of stress in variant I - III in comparison to variant IV. The analysis of the obtained stress results, makes us notice that in both loading cases minimum HMH stress values were obtained in variant IV, which was consequently chosen as best solution. The percentage increase in $\mathrm{HMH}$ stress due to introduced tightening torque in hex bolts for each model variant for two different types of loading were presented in Fig. 3.

a) Load applied directly to the post

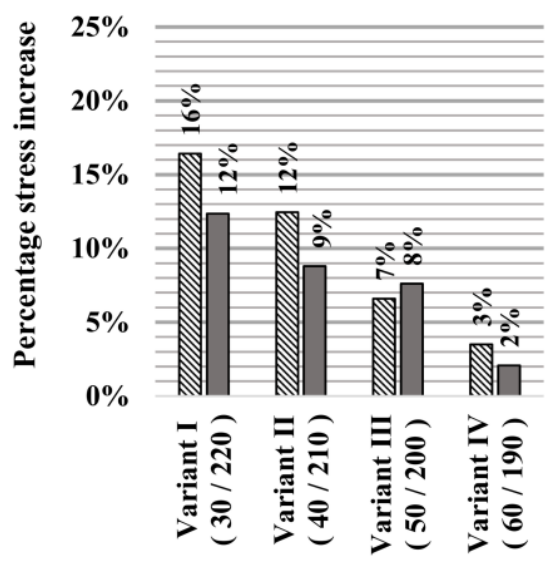

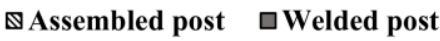

b) Load applied on eccentricity

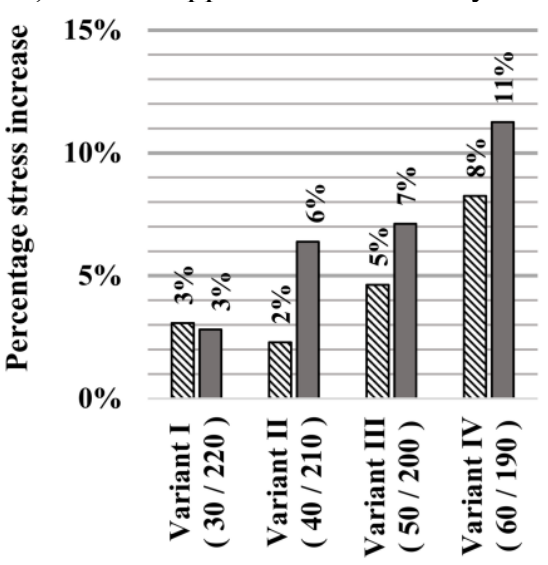

\&Assembled post $\square$ Welded post

Fig. 3. Percentage increase of HMH stress under bolts washers in assembled post and welded post end-plate due to introduced tightening torque into the bolts. Two types of loading: a) load applied directly to the post at $t=0.02 \mathrm{~s}, \mathrm{~b}$ ) load applied on eccentricity at time $t=0.50 \mathrm{~s}$.

On the basis of Fig. 3 one may notice that introduced tightening torque into the bolts in case of load applied directly to the post profile, maximum percentage increase of stress is equal $16 \%$ for variant I, whereas in the case of load applied on eccentricity $11 \%$ maximum increase was obtained in variant IV. It is worth noting that the case of a force applied directly to the post (see Fig. 3a) the influence of tightening torque increases in welded post with closer location of end-plate to the fixed support. In the case of load applied on eccentricity (see Fig. 3b) the influence of tightening torque increases with an increased dimension of end-plate location in relation to the support due to the beam torsion. Given an information that the bolted connection should have been designed in the areas with possibly the lowest bending momentum forces as well as considering HMH stress values under the corner hex bolts washers, variant IV was chosen as the best from analysed solutions.

Despite the fact that Tab. 1 and Tab. 2 show the stress values correspond to the load reach its maximum value and each value exceeded adopted steel yield stress, the graph of stress-time function should also be discussed. In variant IV, where load was applied directly to the HEA profile, values of absolute maximum HMH stress under high tensile bolts with introduced tightening torque in the function of time was presented in Fig. 4. The location of bolts was presented with respect to the YZ-plane in the view of fixed support (see Fig. 2). 

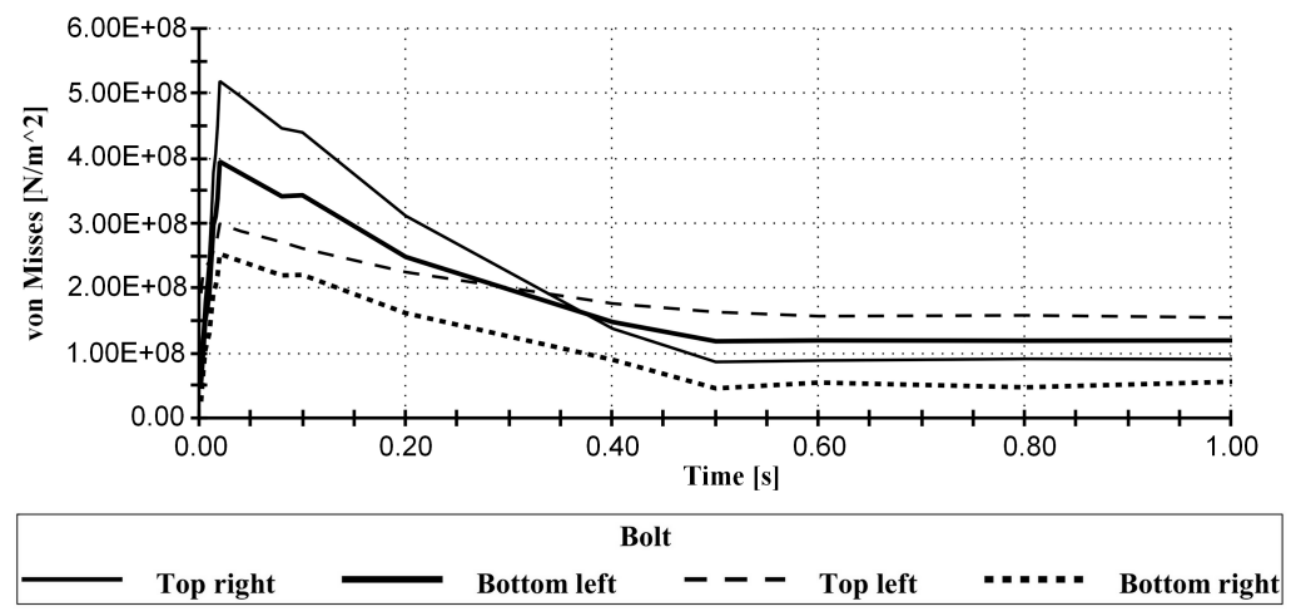

Fig. 4. Absolute maximum Mises stress in the time function for areas located under high tensile bolts washers in variant IV model. HEA profile directly subjected to the impact load. Other parameters: tightening torque equal $1140 \mathrm{Nm}$.

On the basis of Fig. 4 one can state that the applied impact load in time $t=0.02 \mathrm{~s}$, where force reached its maximum value, plastic areas in end-plate connection under bolts washers could be observed. Moreover, plastic work of beam could also be observed near the fixed support and also near the connection of retaining cable. It is worth noting that plastic work of beam elements and end-plate connection was relatively short, approximately around $0.25 \mathrm{~s}$ and also the areas of plastic work were relatively small. Structure material was not ruptured. Considering the curve courses from Fig. 4, one may notice, that after approximately $0.50 \mathrm{~s}$, stresses under hex bolt washers had increased in comparison to the original state, at which only initial stress due to introduced tightening torque had occurred. The mentioned stress increase was linked with the beam deformed shape arisen due to applied impact load - beam had not returned to the original rectilinear shape due to plastic work. In consecutive time steps values of $\mathrm{HMH}$ stress slightly fluctuated which was the result of beam vibrations as an effect of applied impact load, however it should be noted that further load impacts of boulder were neglected in the analysis. The plastic areas and scaled deformation for barrier post subjected to the eccentrically applied load at $t=0.50 \mathrm{~s}$ were presented in Fig. 5.

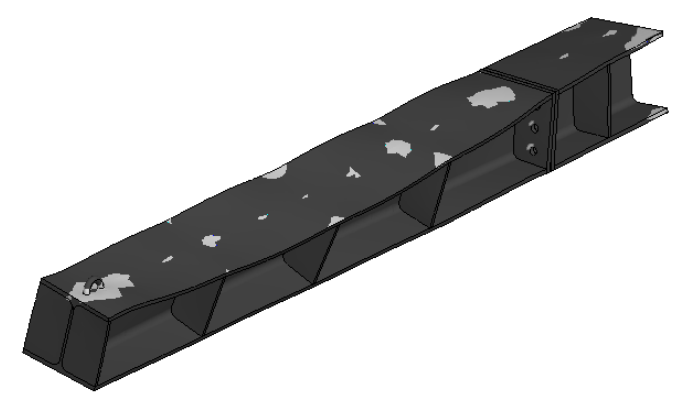

Fig. 5. Plastic areas and scaled deformation in the HEA beam subjected to the eccentrically applied load at $t=0.50 \mathrm{~s}$. 


\section{Conclusion}

The paper presents numerical analysis concerning the influence of high tensile bolts tightening torque on stress distribution in fixed rockfall barrier post with four different locations of end to end-plate connection. Two types of loading were taken into consideration i.e. impact load applied directly onto the HEA post profile and impact load applied on the eccentricity - boulder caught via net.

The analysis shows that the longer distance of end-plate connection from the fixed support the lower HMH stress values under the bolts were obtained. Moreover, it was shown that introduced maximum tightening torque, depending on the end-plate location increased HMH stress by 2 up to $16 \%$ under high tensile bolts in case of load applied exactly on barrier post, whereas in eccentrically loaded barrier by 2 to $11 \%$, respectively. Despite that in both loading cases, when load reached its maximum value stress results exceeded the steel yield strength, the observed plastic areas were relatively small and material structure was not ruptured in the chosen model variant, where end-plate connection was distanced by $0,60 \mathrm{~m}$ from the fixed support. The numerical models presented in the paper can be only regarded as prototypes. Hence further analysis and model modifications should be considered.

\section{References}

1. N. Matsuokaa, H. Sakaib, Geomorphology 28, 309-328 (1999)

2. J. Gardner, Albertan Geographer 6, 15-20 (1977)

3. F. Letto, F. Perri, F. Cella, Catena 145, 301-315 (2016)

4. Y. Kobayashi, E. L. Harp, T. Kagawa, Rock Mechanics and Rock Engineering 23, $1-20(1990)$

5. G. B. Crosta, F. Agliardi, Natural Hazards and Earth System Sciences 4, 583-598 (2004)

6. H. Aksoy, M. Ercanoglu, Natural Hazards and Earth System Sciences 6, 941-954 (2006)

7. K. Thoeni, A. Giacomini, C. Lambert, S. W. Sloan, J. P. Carter, International Journal of Rock Mechanics and Mining Sciences 68, 107-119 (2014)

8. F.Agliardi, G.B.Crosta, International Journal of Rock Mechanics and Mining Sciences 40, 455-471 (2003)

9. https://www.fastenermart.com/files/metric_tighten_torques.pdf (date accessed: $20^{\text {th }}$ December 2017)

10. T. Moon, J. Oh, B. Mun, Engineering Geology 172, 41-56 (2014)

11. S. de Miranda, C. Gentilini, G. Gottardi, L. Govoni, A. Mentani, F. Ubertini, Engineering Structures 85, 83-94 (2015) 